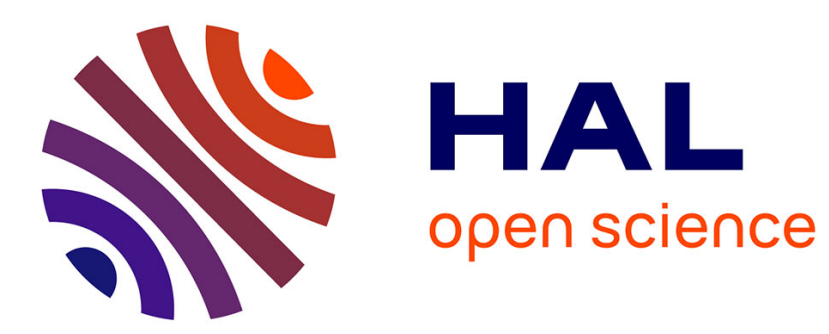

\title{
On the likelihood of past tense situations still being the case at the time of speaking
}

Ilse Depraetere

\section{To cite this version:}

Ilse Depraetere. On the likelihood of past tense situations still being the case at the time of speaking. ITL Review of applied linguistics, 1996, 113-114, pp.335-348. halshs-00625766

\section{HAL Id: halshs-00625766 \\ https://shs.hal.science/halshs-00625766}

Submitted on 22 Sep 2011

HAL is a multi-disciplinary open access archive for the deposit and dissemination of scientific research documents, whether they are published or not. The documents may come from teaching and research institutions in France or abroad, or from public or private research centers.
L'archive ouverte pluridisciplinaire HAL, est destinée au dépôt et à la diffusion de documents scientifiques de niveau recherche, publiés ou non, émanant des établissements d'enseignement et de recherche français ou étrangers, des laboratoires publics ou privés. 
ŠIKRA, J. (1992): "Dictionary Defining Language", in Tommola, Varantola, Salmi-Tolonen \& Schopp (eds) EURALEX'92 Proceedings I-II, Fifth EURALEX International Congress, Studia Translatologica, Ser.A, Vol.1, University of Tampere, pp.295-300.

SinCLAIR, J. (ed.) (1987): Collins Cobuild English Language Dictionary, HarperCollins Publishers, Glasgow.

WILKS, Y., SLATOR, B., GuTHRIE, L. (1996): Electric Words: Dictionaries, Computers, and Meanings, The MTT Press, A Bradford Book, Cambridge, Massachusetts.

1995. ITL Review of applied linguistics 113-114.

\section{On the likelihood of past tense situations still being the case at the time of speaking (1)}

Ilse DEPRAETERE

Lille III

\section{Abstract}

Several linguists have pointed out that the past tense has the implicature that the situation it refers to is no longer the case at the moment of speaking (cf. John lived in London in 1985, but he no longer does). In this article, it is argued that in certain types of sentences the implicature associated with the past tense is more likely to be cancelled than in others. It is shown how (un)boundedness, (a)telicity and the status of adverbials in terms of given or new influence the likelihood of a past tense situation still/no longer being the case at the moment of speaking.

Although the claim that the situations ${ }^{(2)}$ referred to in sentences in the past tense ${ }^{(3)}$ are not necessarily over at the time of speaking may seem obvious, the self-evidence of this observation is not taken for granted by everyone, witness the fact that in the leading descriptive grammar of English, The Comprehensive Grammar of the English Language, it is argued that one of the two features of meaning of the past tense is that 'the event/state must have taken place in the past, with a gap be-

(1) I wish to thank prof. R. Declerck for his comments on an earlier version of this paper.

(2) The term situation is used to refer to the "various "things' that can be expressed in a clause (viz. actions, processes, states, events ...)" (DECLERCK 1991: 14)

(3) From now onwards, I will use the phrase past tense situations as an abbreviation of situations described by sentences in the past tense. 
tween its completion and the present moment' (QUIRK et al. 1985: 183). COMRIE (1985:41-42), DECLERCK (1991:266) and RIDDLE $(1978: 78,100-101)$ are some of the linguists who have argued against such an approach (cf. also MOMMER 1986:74, SMITH 1982:177, 1983: 486, WOISETSCHLÃGER 1976:34-35); they defend the view that if the past tense conveys the impression that a particular situation is no longer the case at the time of speaking at all, this impression is an implicature and not part of the semantics of the past tense. An approach along those lines explains the cancellability (cf. (1b)) of the implicature associated with (1a):

(1) a. John lived in Paris in 1958 (but he no longer does).

b. John lived in Paris in 1958, and he still does.

At closer sight, it seems that in certain types of sentences, the implicature associated with the past tense is more likely to be cancelled than in others. In this paper, I would like to show how a gradient may be set up reflecting the likelihood of a past tense situation still being the case at the time of speaking. The outer poles are constituted by on the one side, situations that can no longer hold at the time of speaking, and on the other, situations that are likely not to be over at the time of speaking. Before an outline will be given of the factors underlying the gradient, the concepts (a)telicity and (un)boundedness will be defined, as they play a crucial role in setting up the gradient.

\section{1. (A)telicity and (un)boundedness defined}

In DEPRAETERE (1995a), it is shown that the classical distinction between the Aktionsart classes telic and and atelic is not sufficient to explain a number of phenomena relating to the temporal interpretation of sentences. It is argued that the additional concepts of boundedness and unboundedness are necessary to account for some issues relating to the use of tense. This section gives an outline of how these notions should be understood.
The notion (a)telicity is well-established: the situation types which VENDLER (1967) distinguished (activity, state, accomplishment, achievement) can be reduced to a bipartite distinction between atelic situations (i.e. activities and states) on the one hand and telic situations (i.e. accomplishments and achievements) on the other. A predicate is telic if the situation it refers to is described as having an inherent endpoint (cf. (2a) and (2b)) which has to be reached for the situation as it is described in the sentence to be complete and beyond which it cannot continue. Otherwise it is atelic (cf. (3a) to (3c)):

(2) a. She dropped the vase on the floor.

b. The bullet hit the target.

(3) a. Sam just hates his wife.

b. John lived in Paris in 1945.

c. He is walking along the shore.

In the examples (2a) and (2b), there is an endpoint inherent in the situation referred to: as a result of gravity laws, an item that is dropped falls on the ground. Similarly, the force of a shot will result in something being hit. There is no similar built-in limit in the situations referred to in the examples in (3): (3a) and (3b) refer to a state, (3c) is an activity.

A sentence is bounded if the situation it refers to is represented as having reached a temporal boundary (cf. (4a) to (4c)); otherwise it is unbounded (cf. (5a) to (5d)):

(4) a. She collapsed when she heard the news.

b. Susan too has loved Jeremy.

c. Helen lived in London for five years.

(5) a. Philip leaves the office at 5 o'clock sharp.

b. Jennifer is baking a cake for her mother's birthday.

c. Helen is particularly interested in word grammar.

d. Jonathan really adored his little sister.

The punctual character of the situation, together with the use of a nonprogressive form establishes a bounded reading in (4a). In (4b), it is the perfect tense which represents the situation as having temporal 
boundaries and hence as bounded, whereas in (4c), it is the adverbial which imposes a temporal boundary. In (5a), there is reference to a habit of Phil's which is not represented as typical of a limited period of time; accordingly, the sentence is unbounded. In $(5 b)$, the progressive tense represents the telic situation as on-going and not yet over. The sentence in (5c) refers to an unbounded state. The situation in (5d) is referred to in the past tense, which indicates that it lies (or starts in any case) before $\mathrm{t}_{0} \cdot{ }^{\left({ }^{(4)}\right.}$ However, this should not mislead us into classifying this sentence as bounded. In order to assess sentences (e.g. past tense sentences) in terms of (un)boundedness, they should be considered from the point of view of R (REICHENBACH 1947) (in the case of the past tense from the past time that is established in the sentence), rather than from the point of view of the moment of speaking (S). The examples given so far show that the use of a nonprogressive form (cf. (4a)), the presence of an adverbial (cf. (4c)) or the use of a perfect tense which gets an indefinite interpretation ${ }^{(5)}$ (cf. (4b)) may result in boundedness; the use of a progressive form (cf. (5b)) and reference to a habit not limited in time (cf. (5a)) are factors which usually result in an unbounded reading being assigned to a particular sentence. ${ }^{(6)}$ The above parameters interact in the sense that a 'bounding' factor may be overruled by an 'unbounding' factor (or

(4) Following DECLERCK (1991), I will use term temporal zero-point ( $\left.t_{0}\right)$ as an alternative to the time of speaking. The temporal zero-point is defined as the "ultimate 'origin' of all the temporal relations expressed in the sentence, i.e. the time to which all the situations referred to in the sentence are directly or indirectly related, and which is not itself presented as dependent on any other (more basic) time" (1991: 10).

(5) The perfect which gets an indefinite interpretation (DECLERCK 1991:28) is used to locate a situation at some indefinite time within a period up to now. It should be distinguished from the perfect which gets a continuative interpretation (DECLERCK 1991: 31), in which case the situation referred to starts before $t_{0}$ and leads up to it.

(6) NPs, directional PPS and tense may also affect (un)boundedness and/or (a)telicity. Cf. DEPRAETERE (1995a), (1995b) for a more detailed discussion of the different factors that influence a sentence's classification as (un)bounded and (a)telic. Cf. DEPRAETERE (1996) for a survey of the tests that can be used to classify sentences. vice versa). The following example, in which there is both a progressive form and an adverbial is a case in point, i.e. the adverbial overrides the unbounded reading established by the progressive form:

(6) A: When were you looking for June?

B: I was looking for her from two to five.

As the adverbial provides new information, it cancels the unbounding effect of the progressive verb form and imposes a bounded reading. (T)

The definitions and examples given show that (un)boundedness and (a)telicity capture different notions. If a sentence is bounded (unbounded), it does not immediately follow that it is telic (atelic) as well (or vice versa), as is clear from example (4b), which is bounded and atelic, and example (5b), which is unbounded and telic. The sentence in (4c) will be bounded telic or bounded atelic depending on whether or not the period of time referred to was part of the subject's aim.

(Un)boundedness is not to be equated with the aspectual opposition progressive vs. non-progressive. The progressive form indeed establishes an unbounded reading in most cases (cf. (7b), (8b)), but this is not the only way in which an unbounded reading can be arrived at (cf. (7c), (8c))

(7) a.I ate an apple. (bounded telic)

b. I was eating an apple. (unbounded atelic)

c. John eats an apple every day. (unbounded atelic)

(8) a. John lived in London for a year. (bounded atelic) b. John is living in London. (unbounded atelic) c. John lives in London. (unbounded atelic)

(7) The presence of a progressive form does not result in an unbounded reading in examples of the following type either:

(i) Her eyes are red. She's been crying.

(ii) His shoes are dirty. He's no doubt been playing football in the mud.

The so-called explanatory-resultative perfect in (i) and (ii) refers to situations that are completely over at the time of speaking. Therefore, they should be classified as bounded, in spite of a progressive form being used. 
This means that clauses can be classified according to three parameters: 1. bounded or unbounded, 2. telic or atelic (Aktionsart), 3. progressive or non-progressive (aspect). ${ }^{(8)}$

It is also important to add that the concepts under discussion should be applied to representations of situations, i.e. sentences, and not to situations as such: if a child is drawing pictures, this particular situation may be captured by means of the sentence Judith is drawing or Judith is drawing a gnome or still Judith has drawn a gnome. In the first case, the situation is represented as unbounded and atelic; in the second case, it is represented as unbounded and telic; in the last case, it is represented as telic and bounded.

Although the account of (un)boundedness and (a)telicity is incomplete, ${ }^{(9)}$ the above discussion provides us with the necessary concepts to set up the gradient that represents the likelihood of past tense situations (not) lasting up to the moment of speaking.

\section{Factors determining gradient}

First of all, it should be pointed out that discussions dealing with this issue (apart from RIDDLE 1978:82-100) have not sufficiently stressed that the semantics of the clause together with pragmatic knowledge contribute considerably to the likelihood of the implicature (that the situation is no longer the case at the time of speaking) (not) being cancelled:

$$
\text { (9) a. Laura worked on her essays for many hours. }
$$

If the hearer knows that Laura is no longer a student, it will be selfevident to him that the past situation no longer holds. The sentence

(8) Cf. BRINTON (1988: 2-3) for a lucid explanation of the difference between Aktionsart and aspect.

(9) Cf. DEPRAETERE (1995a), (1995b) (1996) for a more elaborate discussion of these notions. will be interpreted as referring to a past habit. The following example is similar:

(9) b. Laura played with her dolls in the garden whenever she had a day off.

The hearer will be in no doubt as to whether or not Laura still plays in the garden if he knows that Laura is now 20 years old. Again, he will interpret the sentence as referring to a past situation which is over. Pragmatic knowledge in this context is meant to refer to the speaker's and hearer's familiarity with the persons and situations referred to. The examples in (10) also show that the pragmatics of the clauses influences the likelihood of the implicature applying to a statement, pragmatics referring to our general knowledge about extra-linguistic situations (e.g. building a house takes more time than writing a letter, living in London is subject to change, whereas having blue eyes is usually unalterable, etc.).

(10) a. Laura was in the kitchen two hours ago.

b. Laura was in the kitchen a minute ago.

It is more likely that Laura is still in the kitchen at the moment of speaking in (10b) than in (10a) provided the adverbial represents old information. The necessity of adding that the adverbial should provide old information will be clear from the following: if $(10 \mathrm{~b})$ is an answer to the question When was Laura in the kitchen? (i.e. the adverbial provides new information), a communicative speaker will reply that she was there a minute ago only if he knows or suspects that Laura is no longer there, which means that the situation no longer holds at the time of speaking.

The semantic contents and pragmatics of the situation are definitely the two most important factors that determine whether or not the situation still holds at $t_{0}$. However, even when the situations that sentences refer to do not differ in terms of pragmatic/semantic likelihood of leading up to the present, there is all the same a gradient in 
the probability that the implicature arises that the past situation no longer holds at the time of speaking:

$-\mathrm{t}_{0}$

Sentence type ' $-t_{0}$ ' (the situation no longer holds at $t_{0}$ ) is the type of clause which excludes the possibility of its situation leading up to to, whereas sentence type ' $+t_{0}$ ' (the situation may still hold at $t_{0}$ ) constitutes the other end of the gradient: the past tense sentence still has the implicature that the situation it refers to does not last up to $t_{0}$, though the likelihood of the implicature being cancelled is greater. The following examples show how the distinction between bounded and unbounded situations, telic and atelic situations and given and new information plays an important role in setting up the gradient:

(a) A telic bounded situation referred to in the past tense necessarily lies completely before $t_{0}$ (cf. DECLERCK 1991:266):

(11) a. She killed her husband.

b. She drove the car into the garage.

(b) Past telic unbounded sentences, which are mostly progressive, exhibit a slightly different pattern:

(12) a. He was painting the house when I visited him.

b. We watched the children while they were making a snowman.

The temporary character of sentences in the progressive makes it unlikely that the situations will still be in progress at $t_{0}$. Moreover, telic situations, unlike atelic situations, have an inherent or natural endpoint; it is part of their semantics that they must eventually come to an end. Our knowledge of the world again plays an important role in deciding whether the situation is still likely to hold at $t_{0}$. Making a snowman does not take up as much time as painting a house and is moreover limited to the wintertime, which implies that the implicature is more likely to be cancelled in (12a) than in (12b). It will be clear that a lot depends on how much time has elapsed between the time referred to and $t_{0}$.

(c) A past atelic situation bounded by the addition of an adverbial providing new information strongly implicates that the situation does not lead up to $t_{0}$ :

(13) A: When did John live in London?

B: He lived in London in 1983. ?? In fact, he still does.

(14) A: When was John at Judith's place?

B: He was there yesterday. ?? In fact, he still is.

Indeed, an important stipulation is that the status of the adverbial in terms of given/new information has an influence on whether or not the situation can lead up to $t_{0}$. If the bounding adverbial provides the requested (new) information, and if the hearer assumes that the speaker conforms to Grice's maxim of Quantity, the situation that is bounded through the addition of an adverbial will be interpreted as being over at $t_{0}$.

(d) If, on the contrary, the adverbial provides given information, there are no restrictions of that kind. The relative unacceptability of B's reply in examples (13) and (14) (in which the adverbial presents new information) as compared with the relative acceptability of B's reply in (15) and (16) (in which the adverbial presents given information) demonstrates that the difference between the sentence types illustrated in (c) and (d) is justified:

(15) A: Where did John live in 1983?

B: In 1983, he lived in London. In fact, he still does.

(16) A: Where was John yesterday?

B: He stayed at Judith's place. In fact, I think he is still there.

Strictly speaking, bounded atelic examples of the type illustrated in (6), in which the adverbial overrides the unbounding effect of the progressive, should be classified under (c). However, it appears that their 
behaviour is not fully similar to that of the bounded atelic examples given in (13) and (14):

(17) a. A: When were you looking for June? $(=(6))$

B: I was looking for her from 2 to five. In fact, I still am.

b A: When was he living in London?

B: He was living there in 1983. In fact, he still does.

Unlike in the case of (13) and (14), the cancellation of the implicature in sentences like those in (17) does not result in questionable acceptability. The difference may be due to the following factor: the progressive indicates that a situation is on-going and temporary and accordingly does not inform us whether B was eventually successful in his attempt to find June. This makes it more likely that the past tense situation is still applicable to the moment of speaking. In other words, examples of this type should be classified with the examples described in section (d).

(e) An atelic unbounded situation not accompanied by an adverbial weakly implicates that the situation no longer holds at $t_{0}$ :

$$
\begin{aligned}
& \text { (18) a. Chris hated everything which made him think of his } \\
& \text { mother. }
\end{aligned}
$$
mother.

Chris may still hate everything that makes him think of his mother (cf. (18a)). However, the speaker decides to focus on the past part of the situation. When an adverbial is used, it is slightly more likely that the situation still holds at $t_{0}$ :

(18) b. At the time, Chris hated everything which made him think of his mother.

If there is no adverbial present, one of the major factors lying at the origin of the implicature (i.e. the adverbial, apart from the tense, picks out a past moment in time and therefore suggests that the situation is no longer applicable at $t_{0}$ ) disappears. This is probably why it is more likely that the situations referred to by sentences of the type in (18a) lead up to $t_{0}$.
SMITH (1991) argues that whereas a stative situation referred to in the past tense may still hold at $t_{0}$, an activity referred to in the past tense can no longer be the case at $t_{0}$ :

(19) a. ? Lily swam in the pond and she may still be swimming. (1991: 106)

b. Jennifer knew Turkish
(a) ... but she has forgotten it all.
(b) ... and she still knows it (1991: 109-110)

As pointed out before, a lot depends on the type of situation referred to. In the following example, for instance, the activity is very likely to be still the case at $t_{0}$ :
(19) c. When I met him in 1972, he was working on what he called the biggest achievement in his life, ... and he is probably still working on it.

In the same way, it may be argued that knowing something can potentially last for a longer time (e.g. a year) than swimming can (one cannot swim continuously for a year). In other words, it is the semantics and pragmatics of the sentence rather than its status in terms of state or activity which accounts for the (non-)cancellation of the implicature associated with the past tense.

The following sets of examples also illustrate the gradient:

(20) a. She wrote a letter on Friday moming. (bounded telic) She was writing a letter on Friday morning. (unbounded telic)

b. When did she write letters? She wrote letters on Friday moming. ?? In fact, she still does. (bounded atelic - adverbial is new information) c. What did she do on Friday morning? She wrote letters on Friday morning. ? In fact, she still does. (bounded atelic - adverbial is old information)

d. She was writing letters at ten o'clock on Friday morning. (unbounded atelic) 
(21) a. When did he teach at Eton?

He taught at Eton from 1983 to 1986 . ?? In fact, he stil does. (bounded atelic - adverbial is new information)

b. What did he do from 1983 to 1986 ?

From 1983 to 1986, he taught at Eton. In fact, he still does. (bounded atelic - adverbial is given information)

c. I met him while he taught at Eton. (unbounded atelic)

It has become clear in the discussion that if we want to set up a hierarchy among the factors that determine whether or not a situation still holds at the moment of speaking, it is (a)telicity which comes first: no matter whether a situation is bounded or unbounded, if it is telic, it is not likely to be still the case at the moment of speaking. As far as atelic situations are concerned, the unbounded ones are more likely to lead up to $t_{0}$ than the bounded ones. Within the last category, a distinction has been made between those bounded through the addition of an adverbial giving new information and those bounded through the addition of an adverbial giving old information. The latter category constitutes the border line with the atelic unbounded situations, which are most likely to refer to situations which still hold at the moment of speaking.

\section{Conclusion}

The claim that the past tense has the implicature that the situation it refers to is no longer the case at $t_{0}$ is not new. However, although several linguists have made this point, no one has ever argued that there is a gradient as regards the possibility of a past tense situation lasting up to the moment of speaking. The gradient may be summarized as follows:

a. telic bounded situations

b. telic unbounded situations

c. atelic situations accompanied by a bounding adverbial providing new information d. atelic situations accompanied by a bounding adverbial providing old information

$+t_{0}$ e. atelic unbounded situations

The above discussion has revealed that pragmatic information, the status of the sentence in terms of (un)boundedness and (a)telicity determine whether it is likely or not that the situation referred to is still the case at the time of speaking. The way in which the bounded reading is brought about (through the presence of adverbials providing new or old information) also influences the likelihood of the implicature (not) being cancelled. 